\title{
INTRODUCING Ergo
}

FRANZ HUBER \& JONATHAN WEISBERG

University of Toronto

\section{The Need for Ergo}

Ergo was created in response to a need for general philosophy journals that are efficient, open access, inclusive, and transparent.

In an informal 20I2 poll asking philosophers to rank general journals by quality, ${ }^{\mathrm{I}}$ just one open access journal appeared in the top Io: Philosophers' Imprint. It was the only open access journal included in the poll.

Of the journals in the top 4 spots, 3 are generally thought to have extremely long wait-times. This perception is supported by the only data publicly available: according to the data volunteered to Andrew Cullison's journal surveys, these 3 journals currently take roughly 5,8 , and 9 months on average to return decisions to authors. Wait-times as long as I or 2 years are not unheard of at 2 of them.

The other of the 4 journals to top the poll returns decisions much faster. But it receives so many submissions that it must close its doors 6 months out of every year. The same is true at the $5^{\text {th }}$-ranked journal in the poll. And the $6^{\text {th }}$ instructs referees to use especially strict standards due to a backlog of accepted papers.

Of the ro journals to top the survey then, the first 6 are compromised either by extended wait-times, or else an overrun of submissions. Since one of the remaining 4 accepts only very short submissions, philosophers looking to publish full-length articles in the discipline's most visible and prestigious venues have only 3 options available year-round where they can count on a reasonable turnaround time.

In a recent series of blog posts, Kieran Healy studied citation patterns in the 4 poll-topping journals previously mentioned. He concluded that "the people being cited in our four journals are, overwhelmingly, white men.” For example, looking at the most-cited items over the last two decades in these four journals, he found only

I. We have reservations about this ranking exercise, but the results serve as a useful proxy for visibility and prestige, important considerations when assessing the status quo. Notably, a later poll ranking general and specialist journals together had virtually identical results in all respects discussed here. 
I9 out of about 500 that were written by women, a ratio of $3.6 \%$. For comparison, Healy notes that $6.3 \%$ were written by a single male philosopher, David Lewis.

Healy also found that metaphysics and epistemology dominated the citations in these journals over the last 20 years, with philosophy of mind and ethics/political coming in a fair bit behind. We estimate that over $75 \%$ of the papers published in these journals last year (2013) were in epistemology, metaphysics, or the philosophy of language (in roughly equal proportions). For comparison, some other fields were represented roughly as follows:

- Ethics (including meta, normative, applied, and action theory): $13 \%$

- Philosophy of Mind: $12 \%$

- Logic: $9 \%$

- Decision Theory: 8\%

- History of Philosophy: $4 \%$

- Philosophy of Science: $3 \%$

- Philosophy of Race: $1 \%$

- Continental Philosophy: r \%

- Feminist Philosophy: ০\%

Yet the PhilPapers survey found ethics and philosophy of mind to be the most populous fields amongst the I, 803 faculty/PhDs who responded. Metaphysics, epistemology, and language did follow soon after in that survey. But philosophers of science and historians of philosophy came next, and not nearly so far behind as they do in these journals. It seems philosophy's most visible venues offer a skewed view of what philosophers are interested in and thinking about.

Few journals rigorously track statistics like those we've been citing, and even fewer publish them. Some journals are also notoriously cryptic about their review practices, not to mention the handling of individual submissions. One can piece together a rough, overall picture using sources like those used here, but it's inevitably fuzzy or incomplete because of this lack of transparency.

The state of affairs we've been describing harms both philosophy and philosophers in various ways, as well as universities and the taxpayers and students who fund them. To note a few of those ways:

- By partnering with publishers instead of open access initiatives at university libraries, we effectively give our work over to middlemen from whom libraries must then buy it back. This costs those libraries millions of dollars every year in subscription fees, money that ultimately comes from taxpayers and tuition-paying students. This practice makes little sense now that publishers do very little to disseminate our work, which is commonly posted online, read, and cited long before it is formally published. 
- By the same means we also perpetuate a model where we are forced to sign over the right to publish our own work to organizations who do little more than copyedit and typeset it (often quite poorly).

- Junior philosophers need to publish visibly and quickly to attain jobs, funding, and tenure. But long wait-times make publishing in philosophy's most visible venues a privilege of those who need it least because their careers are already secure.

- Without clear and up-to-date statistics, authors must rely on word of mouth and volunteer data like that collected by Andrew Cullison to guess where to submit their work and what to expect.

- Without more transparency, the philosophical community can't definitely identify irresponsibly run journals and pressure them to improve.

- Philosophers working in areas that aren't well represented in the most visible venues are marginalized by the implicit suggestion that their work is less important, or of lower quality, than work on the topics that dominate those journals. And similar concerns apply to other demographic dimensions like gender and ethnicity.

- When work in certain subdisciplines is segregated into specialist journals, philosophers working in other areas are less likely to see and benefit from that work.

Ergo was created to help redress these problems via the following measures:

- Ergo's contents are published online and available to anyone with an internet connection. There is no subscription fee or paywall, and submitting to and publishing in Ergo are also free, thanks to the support of our partner libraries and the University of Toronto's Department of Philosophy. Authors who publish in Ergo also retain copyright.

- To achieve short review-times while retaining accuracy, Ergo uses a "distributed" editorial model with a large body of "section editors" (40 at present). Because they are specialists in the areas of the papers they handle, section editors are well-placed to decide how these manuscripts should be handled. And because editors each handle only a dozen submissions per year, they are able to carefully and efficiently usher each submission through the review process.

- Ergo also makes liberal use of "desk rejection". We do not endorse this policy as a universal practice for all journals. Some journals seek not only to evaluate submissions, but also to help authors improve them. We agree that there should be such journals, and we applaud the editors and reviewers at these journals for taking on this laborious task. But we also believe it takes all kinds; there should be places where authors can expect to get a negative verdict and move on quickly if their submission is unlikely to be accepted. 
- Ergo strives to be transparent about its operations in a number of ways. We describe our procedures, policies, and timetable for handling submissions in explicit detail on our website. We also gather and publish statistics about our operations. The first public such report is contained in this document, below, and we plan to continue publishing such reports every six to twelve months on the journal website. We also make a habit of contacting authors to inform them of the circumstances when we fall behind schedule, or when things go otherwise awry. In some cases, we also consult the author about how they would like us to proceed. Finally, we inform reviewers about the outcomes of review processes they contribute to, so that they know their hard work is appreciated and can raise concerns about the outcome.

- Ergo strives to be inclusive in a number of ways. We accept submissions on all philosophical topics and from all philosophical traditions and orientations, without word limit or restrictions in format. We also exhort our editors to keep an eye out for strong papers in all areas and by philosophers of all kinds, to encourage submission to Ergo.

Entrusting all substantive decisions about a manuscript's fate to a specialist in the relevant field mitigates bias against areas sometimes viewed as less central or philosophical.

Ergo uses "triple-anonymous" review to mitigate bias. Standard, doubleanonymous review keeps authors' and reviewers' identities from one another; triple-anonymous review also keeps the author's identity from the editor handling the submission (and vice versa). Editors make several significant choices that affect a submission's fate: whether it is sent out for review, who is asked to review it, and what the ultimate decision on the basis of the reviews should be. Bias can creep in at any of these stages if not controlled.

No doubt there is more we could and should be doing. Some philosophical areas and traditions are not well-represented by our editorial board, some aren't represented at all (though they are equally welcome). The same goes for certain groups of philosophers who face bias and other forms of exclusion. Our first statistical report, below, also suggests further ways in which we are falling short here. We are constantly working to improve and we welcome constructive criticism and suggestions.

\section{The First 9 Months}

\section{I Statistics}

Ergo opened its doors to submissions in July of 20I3. We received I 79 submissions over 9 months as of this writing. 170 of these submissions have seen decisions. 
The initial decisions on these I70 submissions break down as follows:

- Declined: $\mathrm{I} 58$ (93\%)

- Desk rejection: II2 (66\%)

- Declined after external review: 46 (27\%)

- Major revisions requested: 7 (4\%)

- Minor revisions requested: $5(3 \%)$

- Accepted: o

The average time-to-decision was $2 \mathrm{I}$ days; 8 days for desk rejections, 43 days for externally reviewed submissions.

Of the I 2 submissions for which revisions were requested, 6 have so far been resubmitted ( 3 major revisions, 3 minor). 5 of these were accepted ( 3 major, 2 minor), I is still under review.

The 5 accepted papers are:

- "Calibration and Probabilism", by Michael Caie (Syracuse University)

- "Evolutionary and Newtonian Forces", by Christopher Hitchcock (California Institute of Technology) and Joel D. Velasco (Texas Tech University)

- "The Problem of ESEE Knowledge", by John Turri (University of Waterloo)

- "Leibniz's Mill Argument Against Mechanical Materialism Revisited", by Paul Lodge (University of Oxford)

- "The Logic of Mind-Body Identification”, by Bernard Molyneux (University of California, Davis)

The chart below breaks down all I 79 submissions by area, though two methodological notes bear mentioning: (I) each submission is counted under just one area due to limitations in our editorial software, and (2) the area is chosen by the submitting author.

The 5 accepted submissions break down by area as follows:

- Epistemology: 2

- History of Modern Philosophy: I

- Philosophy of Biology: I

- Philosophy of Mind: I

The 7 other submissions for which revisions were requested break down thus:

- Continental Philosophy: 2

- Epistemology: I

- General Philosophy of Science: I

Ergo • vol. I • 2014 


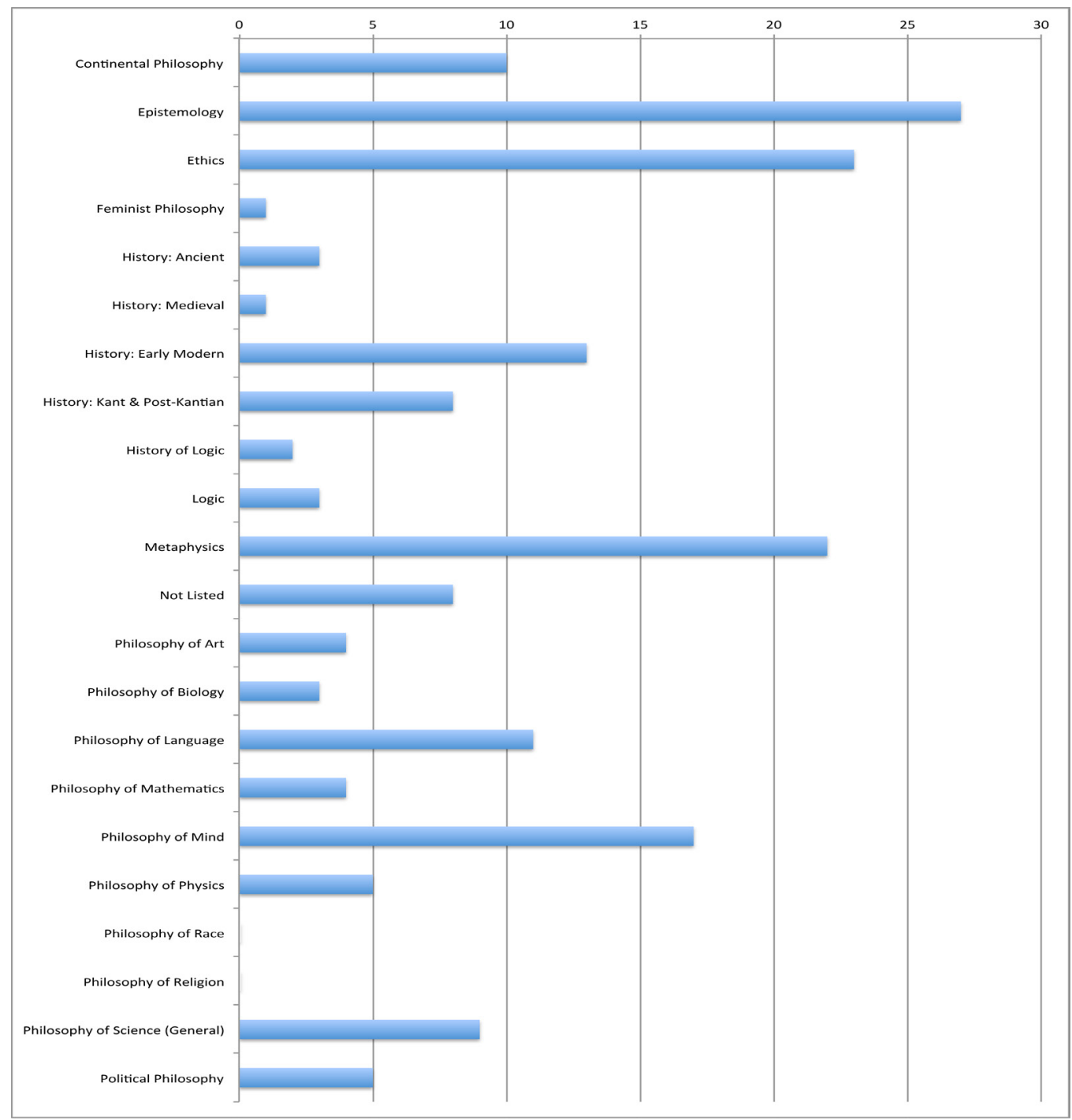

- History of Modern Philosophy: I

- Philosophy of Language: 2

We estimate that $15 \%$ of submitting authors were women, $85 \%$ men. Some notes about methodology again: first, an author was counted each time they submitted a paper, whether as sole author or co-author. Second, when we weren't acquainted with an author personally (the vast majority of cases), we tried to infer gender from publicly available information like conventions surrounding given names and pronouns used on personal/faculty webpages. Where such information wasn't available, the author was not included in the estimate. Third, we assumed 
that authors were either male or female unless we had direct evidence that the author did not identify as either. Given the high probability that such evidence would not have been encountered in a cursory web search, it is quite possible that failures of the gender binary were missed.

\subsection{Discussion}

Ergo has been a tremendous success in several important ways. In other important ways the results have been either mixed or a failure so far.

On the side of success, Ergo is publishing an excellent first set of papers, which are openly accessible. And we are well positioned to continue doing so. We expect this first batch of papers to draw many more high-quality submissions, and our present funding situation is sufficiently solid that we can continue to publish at twice this rate for at least the next two or three years.

Another striking success is the efficiency of Ergo's editorial model. Authors receive decisions very quickly: 8 days on average for desk-rejected submissions, 43 days for externally reviewed submissions. We believe this is a testament to the virtues of distributing the editorial burden and setting clear, tight deadlines for referees and editors.

We do note that a rejection rate of $93 \%$ is quite high, raising the concern that our editorial model is overly conservative. Indeed, each of us as managing editors has had to stand by and watch submissions we would like to have seen published desk rejected instead. Still, our present view is that this is fine in-context: different journals should balance efficiency against other demands differently, so that authors have options and editors can explore and exploit the merits of various models. For now, we will continue with our present model. But we are keeping an eye on this issue, especially in view of the concerns about gender balance discussed below.

On the mixed side, the pool of submissions and submitting authors shows some diversity, but also some serious skew. For example, we've received a good number of submissions in areas sometimes underrepresented in general journals, like continental philosophy, ethics, history, philosophy of art, and philosophy of science. Yet submissions in epistemology are the most numerous, even more so than submissions in all branches of ethics combined. And some areas, like philosophy of race and feminist philosophy, are barely represented at all (though it should be noted that a few submissions engaging significantly with issues of race and gender were submitted under other rubrics). Also, while women are represented in the pool of submitting authors almost in proportion to the gender ratio of working philosophers ( $15 \%$ vs. roughly I6-2I $\%^{2}$ ), women are still underrepresented, and

2. It's difficult to get an exact picture of how women are represented in philosophy. The I62I \% figure stated here is based on Kathryn Norlock's 20I I report to the American Philosophical Association on female philosophy faculty in the United States, as well as the more global PhilPapers 
very badly so relative to the general population. (We haven't gathered data about other important demographic factors, like ethnicity and physical ability, because we aren't yet sure how to do so reliably. But it may well be that similar concerns apply.)

Some of this skew may reflect early perceptions of the journal based on the managing editors, since we are both men specializing in epistemology. (Not surprisingly, many friends and acquaintances working in epistemology and closely related areas readily supported the journal by submitting papers, and we are very grateful to them.) We expect there are other causes too, but we hesitate to speculate on others' behalf. Instead, we want to take this opportunity to encourage submissions from philosophers of all bents and backgrounds, especially those we currently underrepresent. We also welcome and encourage feedback about what we can do to improve and make the journal more attractive to a broader spectrum of philosophers.

Finally, of serious concern is the fact that all 6 authors of the 5 papers accepted so far are men. This could be an anomaly, given the small number of papers accepted. But it's also alarming that all $\mathrm{I}_{3}$ authors of the $\mathrm{I}_{2}$ papers for which revisions were requested are men. No woman has yet to receive any decision other than 'Decline'.

We are embarrassed and disappointed by this outcome. We had hoped that triple-anonymous review and a balanced editorial board would at least result in nearly proportional outcomes by this stage. We still hold out hope that the present outcome is the result of random noise rather than bias, and that things will improve soon. But we are beginning to worry that the measures Ergo takes to combat gender bias do not significantly mitigate it, and may even paradoxically enable it. We welcome input from the philosophical community while we consider how to proceed, especially from those with relevant expertise.

\section{Debts \& Thank Yous}

We owe such tremendous debts to so many people that we can never hope to right the balance. But we can make a beginning by thanking as many people for their outstanding contributions as we can remember to-and by apologizing to the many others we are painfully aware we must be leaving out.

First are our section editors. They are the ones who promptly read, and re-read (and re-read), the piles of submissions as they come in. They are the ones who seek out, recruit, and hound reviewers. They are the ones who agonize and make the

survey results for various research-level subgroups: “Target faculty" "Philosophy faculty or PhD”, and "Philosophy graduate student". 
hard decisions about each manuscript's fate. In short, they do all the real work. It is an honour to work with you:

- Catharine Abell

- Rachael Briggs

- Lara Buchak

- Juan Comesaña

- Eleonora Cresto

- Vincenzo Crupi

- Imogen Dickie

- Catarina Dutilh-Novaes

- Julia Driver

- Kenny Easwaran

- Matt Evans

- Laura Franklin-Hall

- Sebastian Gardner

- Maximilian de Gaynesford

- Helen Hattab

- Thomas Hofweber

- Ole Hjortland

- Daniel Z. Korman

- Michelle Kosch

- Antonia LoLordo

- Christy Mag Uidhir

- Ofra Magidor

- Julia Markovits

- Lionel McPherson

- Christopher Mole

- Jennifer Nagel

- Jill North

- Richard Pettigrew

- Martin Pickavé

- Constantine Sandis

- Adam Sennet

- Nishi Shah

- Quayshawn Spencer

- Meghan Sullivan

- Ásta Sveinsdóttir

- Clinton Tolley

- Robbie Williams

- Wayne Wu 
- Christian Wüthrich

- Jiji Zhang

Now gone from this list but by no means forgotten are L. A. Paul and Brian O'Connor, who bravely joined the ranks for Ergo's initial launch and weathered the rough, early days. A special "thank you" is due to Nick Stang, who generously helped the journal out of an editorial jam when several submissions were orphaned.

A journal is nothing without the authors who submit their work, though. They entrust us with the products of their many painstaking hours of labour, and we are grateful to every author who took a chance on us by submitting a paper. We are especially grateful to them for taking a chance on a newcomer, in many cases out of a selfless desire to support the causes for which Ergo stands. Many of them submitted excellent work only to have it declined, and we are sorry. We hope they will give us a chance to redeem ourselves by continuing to send us their work.

Without the guidance of several more experienced colleagues, we could never have successfully navigated the minefield of setting up a journal's infrastructure. Arthur Ripstein shared invaluable wisdom about editing and publishing a journal. And as chair of the Department of Philosophy at the University of Toronto, he arranged for the funding that makes open access to Ergo possible. The founders and editors of Philosophers' Imprint, David Velleman and Stephen Darwall, provided plenty of generous advice too, but they also provided crucial inspiration. Imprint blazed the open access trail for journals like Ergo. Without their pioneering work, a journal like Ergo could not become so successful so quickly; indeed, we doubt it would exist at all. Similar guidance and inspiration came from Ed Zalta and Collin Allen, whose work on the Stanford Encyclopedia of Philosophy also blazed trails Ergo is following. And Peter Ludlow, along with Arthur and David, advocated on our behalf to secure the partnership we enjoy with our publisher at the University of Michigan's library, Michigan Publishing.

It took the wisdom of many philosophers much more knowledgeable than us to assemble the staggeringly talented and efficient group of section editors listed above. For their generous advice and support in this regard, we wish to thank Donald Ainslie, Rachel Barney, Luc Bovens, Victor Caston, Derrick Darby, Alan Hájek, Sally Haslanger, Tom Hurka, Brad Inwood, Jon Kvanvig, Brian Leiter, David Manley, Frederick Neuhouser, Arthur Ripstein, Mathias Risse, Michael Rosen, Marleen Rozemond, Tommie Shelby, Ted Sider, Paul Taylor, Sergio Tenenbaum, Jennifer Whiting, and Dean Zimmerman. Many of our section editors themselves contributed expert guidance here too, and their advice has always proven true.

We are also immensely grateful to the patient and hardworking folks at the two libraries where Ergo is edited and published. The University of Toronto's libraries host the online editorial system where Ergo receives and reviews submissions, and 
the people who maintain this system have been extraordinarily patient and helpful as we bumble through learning the ropes. Thanks to Rea Dvakos, Sarah Forbes, Andrew McAlorum, and especially Sean Zhao for his hard work customizing the system to enable triple-anonymous review. The University of Michigan's libraries handle the actual publication of accepted manuscripts, and we are extremely fortunate to be partnered with such an efficient and conscienscious organization. Our many thanks to Jason Colman, Jillian Downey, Kevin Hawkins, Rebecca Welzenbach, and Kelly Witchen for guiding us through the setup process and patiently handling our many inept queries and requests.

Thanks also to our outstanding copyeditors, Robert Lehnert and Kevin Kuhl, and to Anja Oberländer for her generous consultation about publication options.

Finally, JW would like to thank Kristen Aspevig for her boundless support, advice, encouragement, and sacrifice. He would also like to blame FH for getting him into this mess, while also thanking him for doing far more than his fair share of the work. The journal would be an absolute disaster without his careful attention and limitless energy. FH would like thank JW for having created Ergo effectively on his own, from the proposal for our publisher to convincing our chair to the expertise in programming to this very editorial, as well as for always resolving the really tricky situations with utmost diplomatic elegance and eloquence. FH's contribution mainly consists in letting his impatience create these tricky situations, as our editors know all too well. FH and JW would both like to thank them again for doing all the real work. 